\title{
Epigenetic silencing of miR-340-5p in multiple myeloma: mechanisms and prognostic impact
}

\author{
Zhenhai Li ${ }^{1}$, Kwan Yeung Wong', George A. Calin², Wee-Joo Chng ${ }^{3,4,5}$, Godfrey Chi-fung Chan ${ }^{6}$ and \\ Chor Sang Chim ${ }^{1 *}$
}

\begin{abstract}
Background: miR-340-5p, localized to 5q35, is a tumor suppressor miRNA implicated in multiple cancers. As a CpG island is present at the putative promoter region of its host gene, RNF130, we hypothesized that the intronic miR340-5p is a tumor suppressor miRNA epigenetically silenced by promoter DNA methylation of its host gene in multiple myeloma.

Results: By pyrosequencing-confirmed methylation-specific PCR, RNF130/miR-340 was methylated in 8/15 (53.3\%) myeloma cell lines but not normal plasma cells. Methylation correlated inversely with the expression of both miR340-5p and RNF130. In completely methylated WL-2 and RPMI-8226R cells, 5-AzadC treatment led to demethylation and re-expression of miR-340-5p. In primary samples, RNF130/miR-340 methylation was detected in 4 (22.2\%) monoclonal gammopathy of undetermined significance, 15 (23.8\%) diagnostic myeloma, and 7 (23.3\%) relapsed myeloma. RNF130/miR-340 methylation at diagnosis was associated with inferior overall survival (median 27 vs. 68 months; $P=3.944 \mathrm{E}-5)$. In WL-2 cells, overexpression of miR-340-5p resulted in reduced cellular proliferation [MTS, $P=0.002$; verified in KMS-12-PE $(P=0.002)$ and RPMI-8226R $(P=2.623 \mathrm{E}-05)$ cells], increased cell death (trypan blue, $P=0.005)$, and enhanced apoptosis by annexin V-PI staining. Moreover, by qRT-PCR, overexpression of miR-340-5p led to repression of both known targets (CCND1 and NRAS) and bioinformatically predicted targets in MAPK signaling (MEKK1, MEKK2, and MEKKK3) and apoptosis (MDM4 and XIAP), hence downregulation of phospho-ERK1/2 and XIAP by Western blot. Furthermore, by qRT-PCR, in CD138-sorted primary samples $(n=37)$, miR-340-5p and XIAP were inversely correlated $(P=0.002)$. By luciferase assay, XIAP was confirmed as a direct target of miR-340-5p via targeting of the distal but not proximal seed region binding site.
\end{abstract}

Conclusions: Collectively, tumor-specific methylation-mediated silencing of miR-340-5p is likely an early event in myelomagenesis with adverse survival impact, via targeting multiple oncogenes in MAPK signaling and apoptosis, thereby a tumor suppressive miRNA in myeloma.

Keywords: Multiple myeloma, miR-340-5p, DNA methylation, XIAP, Overall survival

\section{Background}

Multiple myeloma is the second most common blood cancer, accounting for approximately $10 \%$ of all hematologic malignancies [1]. Patients with myeloma are often preceded by an asymptomatic pre-malignant stage of monoclonal gammopathy of undetermined significance (MGUS), which

\footnotetext{
* Correspondence: jcschim@hku.hk

${ }^{1}$ Department of Medicine, Queen Mary Hospital, The University of Hong

Kong, Pokfulam Road, Pokfulam, Hong Kong

Full list of author information is available at the end of the article
}

progresses into symptomatic myeloma at a rate of $1 \%$ per year [2]. Genetically, about half of patients with myeloma carries a non-hyperdiploid karyotype, which is associated with recurrent translocations involving immunoglobulin gene located at $14 \mathrm{q} 32$, whereas the other half carries a hyperdiploid (HPRD) karyotype, characterized by trisomies of odd number chromosomes [3]. Apart from chromosomal copy number alterations, recurrent genetic mutations have been identified, in particular, amongst genes involved in RAS (NRAS, KRAS, and BRAF), NF-kB

(C) The Author(s). 2019 Open Access This article is distributed under the terms of the Creative Commons Attribution 4.0 International License (http://creativecommons.org/licenses/by/4.0/), which permits unrestricted use, distribution, and 
(TRAF3, CYLD, and LTB), and TP53 (TP53, ATM, and $A T R$ ) signaling pathways [4-6].

MicroRNAs (miRNAs) are endogenous, single-stranded, small non-coding RNAs of $\sim 22 \mathrm{nt}$ in length $[7,8]$. Functionally, a miRNA will target and suppress the expression of their target protein-coding genes by complementary binding of the seed region, i.e., the second to seventh nucleotides, to the seed region binding site (SRBS) in the 3 '-UTR of the targeted mRNAs of protein-coding genes, leading to translational blockade or mRNA degradation [9]. Deregulated miRNA expression has been found in cancers including hematologic malignancies $[10,11]$, in which oncogenic miRNAs targeting tumor suppressor genes are upregulated, whereas tumor suppressive miRNAs targeting oncogenes are downregulated $[8,11]$. For instance, overexpression of $m i R-21$, of which PTEN was a direct target, led to the activation of PI3K/AKT signaling pathway, and hence, $m i R-21$ is an oncomiR promoting cellular proliferation [12]. On the other hand, $m i R-30 c$, targeting BCL9, has been shown downregulated in myeloma. BCL9 is an essential effector component for transcription of oncogenic Wnt target genes [13]. Moreover, restoration of $m i R-30 c$ led to inhibition of cell proliferation, invasion, and migration in addition to enhancing apoptosis of myeloma cells, hence a tumor suppressor miRNA [14].

DNA methylation refers to the addition of a methyl $\left(-\mathrm{CH}_{3}\right)$ group to carbon five position of the cytosine ring in a CpG dinucleotide [15]. CpG dinucleotides may cluster as a $\mathrm{CpG}$ island, which is defined as any genomic region of $>200$ bp with a high GC content of $>50 \%$ and a high ratio of observed/expected CpG $>0.60[16,17]$. In the mammalian genome, promoter-associated CpG islands are localized to or in close proximity to the promoter region of more than half of the human genes [18] and involved in the regulation of gene expression by DNA methylation [19]. In normal cells, the majority of promoter-associated CpG islands are unmethylated, associated with a euchromatin configuration, and hence transcriptionally ready or active for gene expression [20]. Conversely, $\mathrm{CpG}$ islands/sites in the intergenic regions, imprinted regions, and $\mathrm{X}$-chromosome are hypermethylated, leading to repression of repetitive elements, such as SINE and LINE elements, imprinted genes, and X-linked genes respectively [19]. In contrast to normal cells, cancer cells are characterized by global DNA hypomethylation and locus-specific hypermethylation of promoterassociated $\mathrm{CpG}$ islands of tumor suppressor genes or miRNAs, resulting in downregulation, and hence loss of tumor suppressor functions [8,21, 22]. For instance, in myeloma, tumor suppressive $m i R-34 b / c$ [23], miR-203 [24], and miR-129-2 [25] have been shown to be silenced by promoter DNA methylation. Moreover, epigenetic silencing of miR-137 has been found to correlate with shorter progression-free survival in myeloma [26].
miR-340-5p, localized to $5 \mathrm{q} 35$, is embedded in the second intron of its host gene, RNF130, and has been shown to be a tumor suppressor downregulated in several cancers, such as breast cancer [27], ovarian cancer [28], and hepatocellular carcinoma [29]. In hepatocellular carcinoma, overexpression of $m i R-340-5 p$ by oligo transfection resulted in inhibition of cell proliferation, migration, and invasion in vitro and suppression of tumor growth in vivo by directly targeting Janus kinase 1 [29]. As a CpG island is present at the promoter region of its host gene, RNF130, we hypothesized that $m i R-340-5 p$ is an intronic tumor suppressor miRNA epigenetically silenced by $R N F 130 / m i R-340$ promoter DNA hypermethylation in multiple myeloma (Additional file 3: Figure S3).

\section{Results}

Methylation of RNF130/miR-340 in healthy controls and human myeloma cell lines (HMCLs)

Methylation-specific PCR (MSP) was carried out to examine methylation of RNF130/miR-340 in the bisulfite-converted DNA of healthy controls [peripheral blood $(n=10)$ and CD138-sorted bone marrow plasma cell $(n=2)]$ and HMCLs $(n=15)$. Direct sequencing of the M-MSP products from positive control with methylated DNA confirmed the completeness of bisulfite conversion and MSP specificity, as indicated by conversion of all unmethylated cytosines into thymidines after PCR, whereas all methylated cytosines remained unchanged (Fig. 1a). None of the healthy controls showed methylation of RNF130/miR-340 (Fig. 1b). By contrast, in HMCLs, RNF130/miR-340 was completely methylated (MM; M-MSP positive but U-MSP negative) in WL-2 and RPMI-8226R; partially methylated (MU; both M-MSP and U-MSP positive) in JJN-3, KMS-12-PE, MOLP-8, OCI-MY5, OPM-2, and RPMI-8226; and completely unmethylated (UU; M-MSP negative but U-MSP positive) in LP-1, NCI-H929, U-266, MMKKF, MMLAL, KMS-11/ BTZ, and OPM-2/BTZ (Fig. 1c). Moreover, these MSP methylation statuses (MM, MU, and UU) were verified using quantitative bisulfite pyrosequencing, which showed that completely methylated HMCLs were associated with a higher methylation level between 62.8 and $94.6 \%$, partially methylated HMCLs carried an intermediate methylation level of 17.0 to $35.4 \%$, and completely unmethylated HMCLs were associated with a lower methylation level from 5.2 to $8.6 \%$ (Additional file 1: Figure S1). These data suggested that RNF130/miR-340 was methylated in a tumor-specific manner in myeloma.

\section{Methylation and expression of $m i R-340-5 p$ and its host gene RNF130 in HMCLs}

To study if methylation of RNF130/miR-340 was correlated with downregulated expression of $m i R-340-5 p$ and 


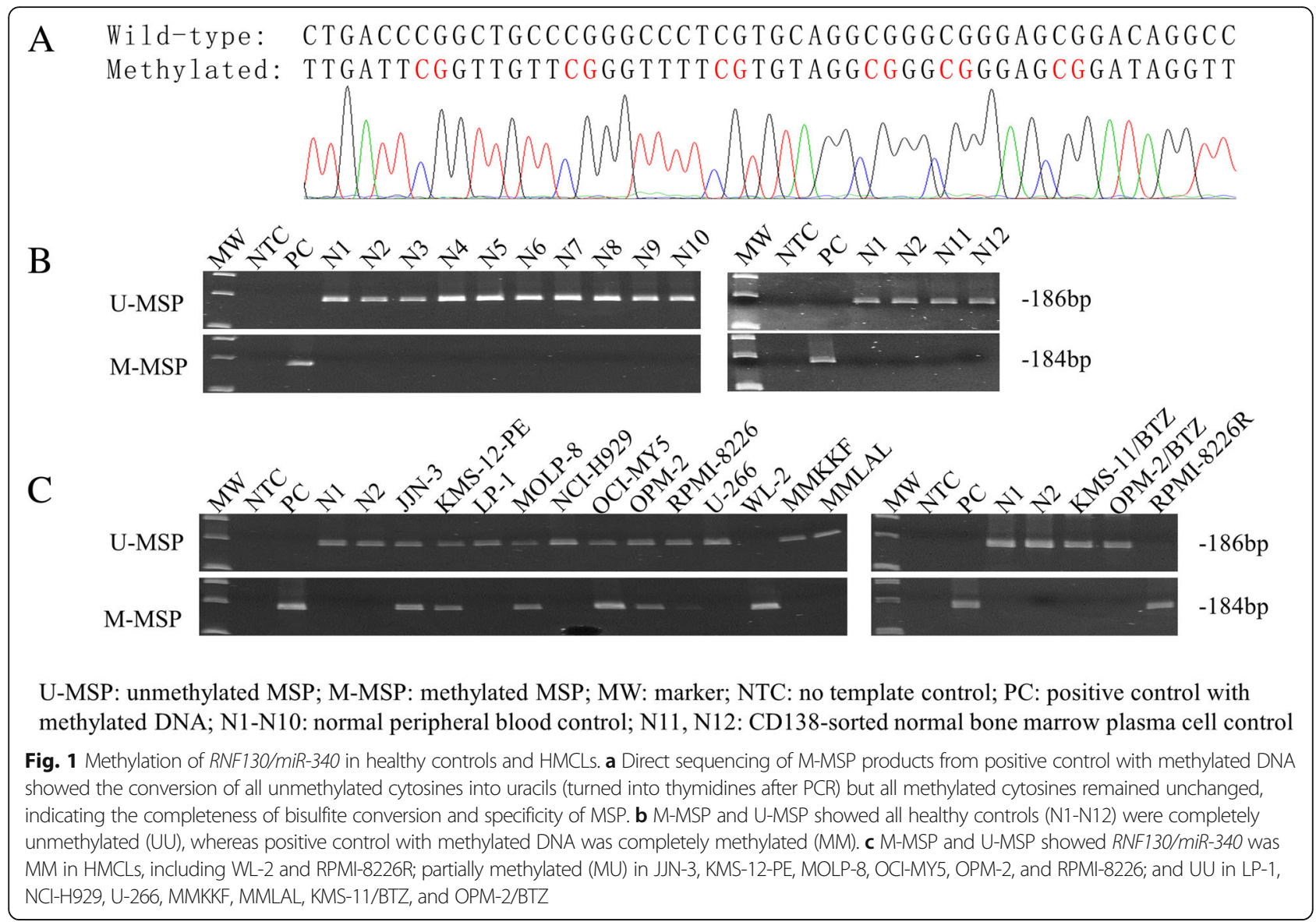

its host gene, RNF130, qRT-PCR was employed to measure the expression levels of miR-340-5p and RNF130 in HMCLs. Results showed that HMCLs with methylation of RNF130/miR-340 had significantly lower expression levels of both miR-340-5p (Fig. 2a; MM vs. UU, $P=$ $0.026 ; \mathrm{MM}+\mathrm{MU}$ vs. $\mathrm{UU}, P=0.002$ ) and RNF130 (Fig. 2b; $\mathrm{MM}$ vs. $\mathrm{UU}, P=0.006 ; \mathrm{MM}+\mathrm{MU}$ vs. $\mathrm{UU}, P=2.54 \mathrm{E}-4$ ) than HMCLs completely unmethylated for RNF130/ $m i R-340$. Moreover, to examine if $m i R-340-5 p$ was co-expressed with RNF130, in HMCLs, the expression of miR-340-5p was plotted against RNF130, and a concordant expression of miR-340-5p and RNF130 was demonstrated (Fig. 2c; $R^{2}=0.9267, P=9.431 \mathrm{E}-09$ ).

To further testify if promoter DNA methylation resulted in downregulation of miR-340-5p, WL-2 and RPMI-8226R cells, which were completely methylated for RNF130/miR-340, were treated with 5-AzadC, a demethylation agent. Upon treatment with 5-AzadC, the promoter of RNF130/miR-340 was demethylated as evidenced by the emergence of U-MSP signal on both day 3 and day 6 (Fig. 2d, e). Moreover, by qRT-PCR, mature miR-340-5p was simultaneously re-expressed by 1.4- to 8.8 -fold on day 3 and by 5.6 - to 49.1-fold on day 6 (Fig. 2f, g). Hence, in myeloma cells, methylation-mediated silencing of miR-340-5p was reversible.
Methylation and expression of RNF130/miR-340 in primary bone marrow samples of MGUS, diagnostic myeloma, and relapsed myeloma

By MSP, methylation of RNF130/miR-340 was detected in 4 (22.2\%) MGUS, 15 (23.8\%) diagnostic myeloma, and 7 (23.3\%) relapsed myeloma primary bone marrow samples (Fig. 3a). Methylation frequency of RNF130/miR-340 was not significantly different among those consecutive clinical stages of myeloma (MGUS vs. diagnostic myeloma: $P=1.000$; diagnostic myeloma vs. relapsed myeloma: $P=1.000$ ). However, in contrast to the absence of methylation in normal, the appearance of methylation in MGUS and a comparable frequency in consecutive stages from MGUS to diagnostic myeloma and to relapsed myeloma indicated it might be an early event in the pathogenesis of myeloma. Moreover, among 26 diagnostic samples with paired CD138-sorted RNA samples, methylation of RNF130/miR-340 had a trend of associating with lower expression of $m i R-340-5 p$ (Fig. $3 \mathrm{~b} ; P=0.223$ ).

Interestingly, by Kaplan-Meier analysis, the projected overall survival (OS) of diagnostic myeloma patients with and without RNF130/miR-340 methylation was $33.3 \%$ and $75.0 \%$ respectively, and patients with 


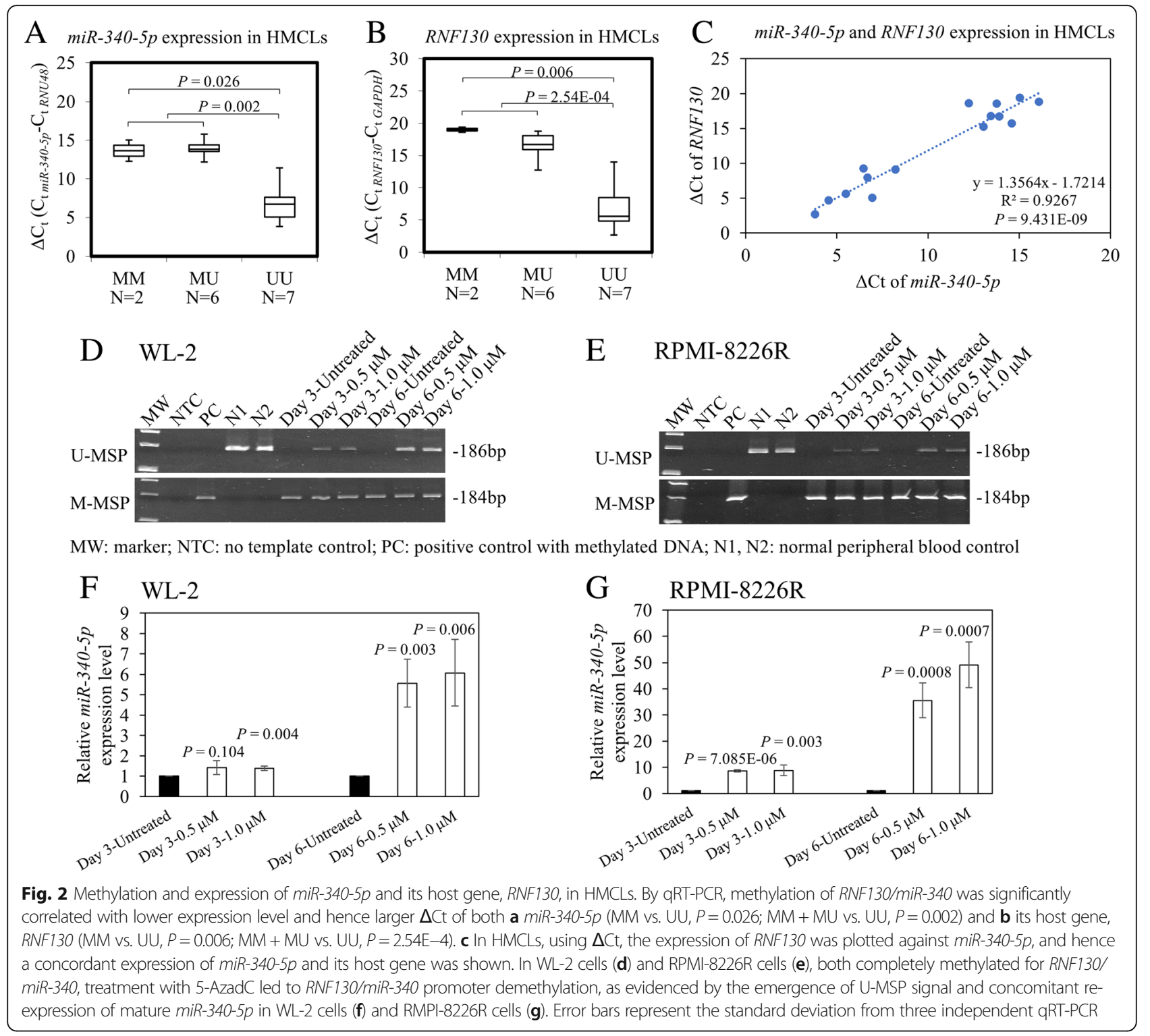

RNF130/miR-340 methylation $(n=15)$ showed significantly shorter OS than patients without RNF130/ miR-340 methylation $(n=48)$ (Fig. 3c; median 27 vs. 68 months; $P=3.944 \mathrm{E}-5)$. By Cox regression multivariate analysis, $m i R-340-5 p$ methylation $(P=0.002$; hazard ratio 8.983 ; $95 \%$ confidence interval $2.203-$ 36.630) was shown to be an adverse prognostic factor of OS independent of ISS $(P=0.652)$, age $(P=0.331)$, sex $(P=0.690)$, isotype $(P=0.198)$, high LDH $(P=$ $0.367)$, and high-risk karyotype $(P=0.438)$ in primary myeloma samples at diagnosis. Moreover, methylation of RNF130/miR-340 was preferentially detected in IgD and IgG myeloma $(P=0.016)$, but not associated with gender $(P=0.383)$, age $(P=0.933)$, or ISS stage $(P=$ $0.985)$.

\section{Tumor suppressive function of miR-340-5p in myeloma} cells

As methylation-mediated silencing of miR-340-5p was frequently detected in HMCLs and primary samples, we postulated that it might act as a tumor suppressor. By MTS assay, as compared to scramble control, overexpression of miR-340-5p resulted in reduced cellular proliferation in KMS-12-PE by $15.7 \%(P=0.002)$, WL-2 by $17.3 \%(P=0.002)$, and RPMI- $8226 \mathrm{R}$ by $22.8 \%(P=$ 2.623E-05) (Fig. 4a). Moreover, in WL-2 cells, an increase of dead cells by $3.73 \%$ (Fig. $4 \mathrm{~b} ; P=0.005$ ) and induction of apoptosis by $9.60 \%$ (Fig. 4c) were also demonstrated using trypan blue staining and annexin V-PI analysis respectively, suggesting a tumor suppressive role of miR-340-5p in myeloma cells. 


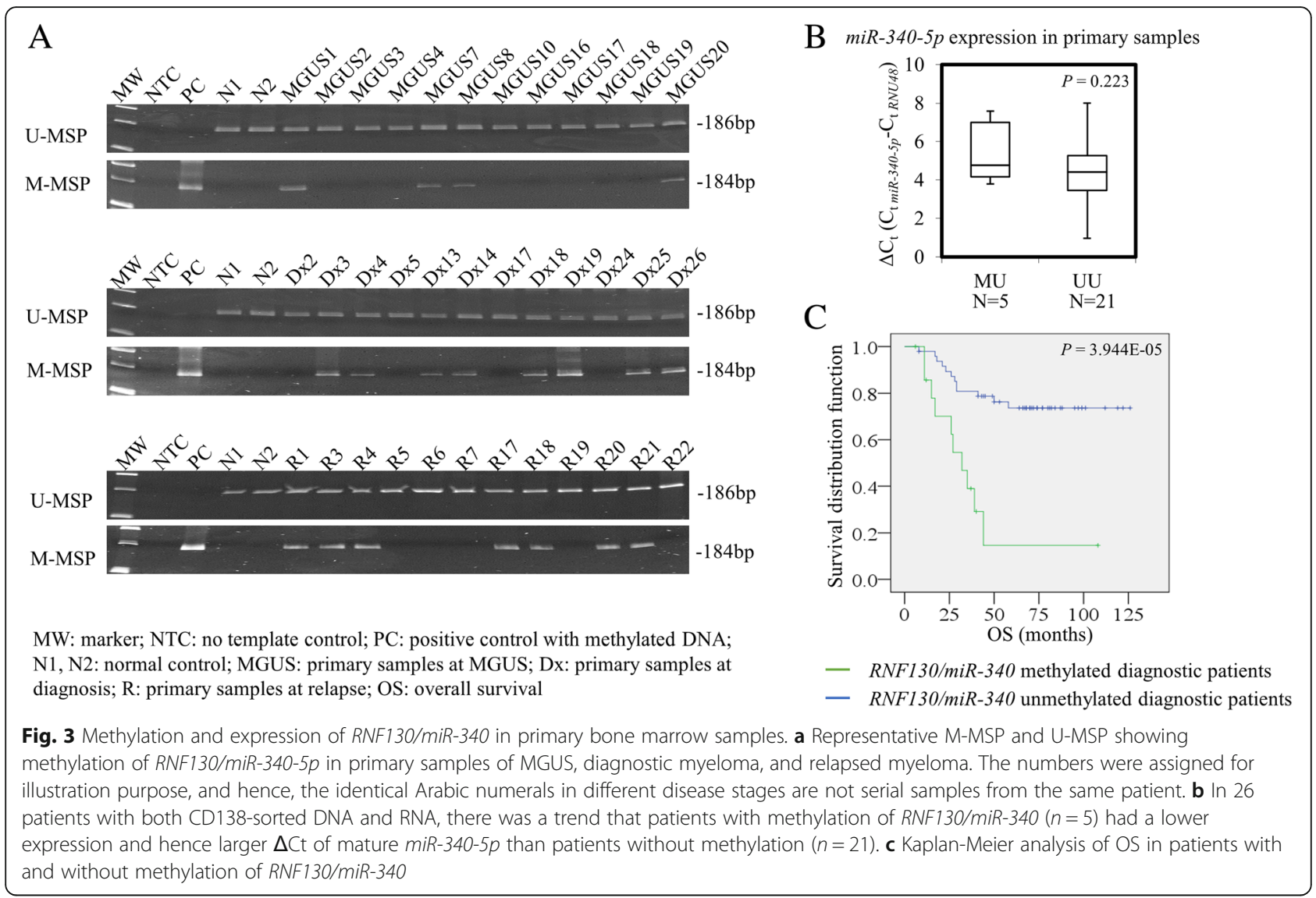

\section{Overexpression of miR-340-5p downregulated multiple target genes involved in MAPK signaling and apoptosis} To further elucidate the mechanism of $m i R-340-5 p$ in the regulation of cellular proliferation and apoptosis, the expression of previously validated known target genes, including NRAS [30], MDM2 [31], NFKB1 [28], and CCND1 [32], were studied. Moreover, by miRWalk2.0 [33], which is a bioinformatics platform combining several well-known miRNA target prediction algorithms, including miRanda, miRDB, TargetScan, and PITA, additional potential direct targets with known oncogenic properties, including MEKK1, MEKK2, MEKKK3, MDM4, and XIAP, were predicted and further studied.

Of the known targets of $m i R-340-5 p$, overexpression of $m i R-340-5 p$ resulted in significant downregulation of CCND1 and NRAS and all of the predicted target genes, including $M E K K 1, M E K K 2, M E K K K 3, M D M 4$, and XIAP (Fig. 5a). Moreover, by Western blot, protein expression level of XIAP, which is an inhibitor of apoptosis, and p-ERK1/2, which is a key effector downstream to NRAS, MEKK1, and MEKKK3 in MAPK signaling, were decreased by $27 \%$ and $60 \%$ respectively upon overexpression of $m i R-340-5 p$ (Fig. 5b). Furthermore, in CD138-sorted primary samples $(n=37)$, a higher expression level of $m i R-340-5 p$ was significantly correlated with a lower level of XIAP by qRT-PCR (Fig. $5 \mathrm{c}, R^{2}=$ $0.2466, P=0.002)$. These data suggested that $m i R-340-5 p$ might exert its tumor suppressive function by regulating multiple oncogenic target genes involved in MAPK signaling and apoptotic pathways.

\section{Identification of XIAP as a direct target of miR-340-5p}

As overexpression of $m i R-340-5 p$ had induced a significant increase of apoptosis in myeloma cells (Fig. 4d), luciferase reporter assay was employed to verify if XIAP, an inhibitor of apoptosis, is a direct target of miR-340-5p. By bioinformatics, two conserved $m i R-340-5 p$ SRBSs were identified in the 3'-UTR of XIAP (Additional file 2: Figure S2A and Fig. 6a). DNA fragments containing either wild-type or mutant SRBS were generated and cloned into a dual firefly/ Renilla luciferase reporter vector (Additional file 2: Figure S2B and Fig. 6b). For each SRBS, luciferase vector containing the wild-type or mutant $3^{\prime}$-UTR of XIAP was co-transfected with $m i R-340-5 p$ mimics or scramble control into Hela cells for luciferase assay at $48 \mathrm{~h}$. Upon co-transfection of the wild-type SRBS 1, which was predicted to form 7 mer-A1 binding with $m i R-340-5 p$, overexpression with $m i R-340-5 p$ mimics resulted in comparable luciferase signal as compared with scramble control (Additional file 2: Figure S2C). Moreover, co-transfection of 


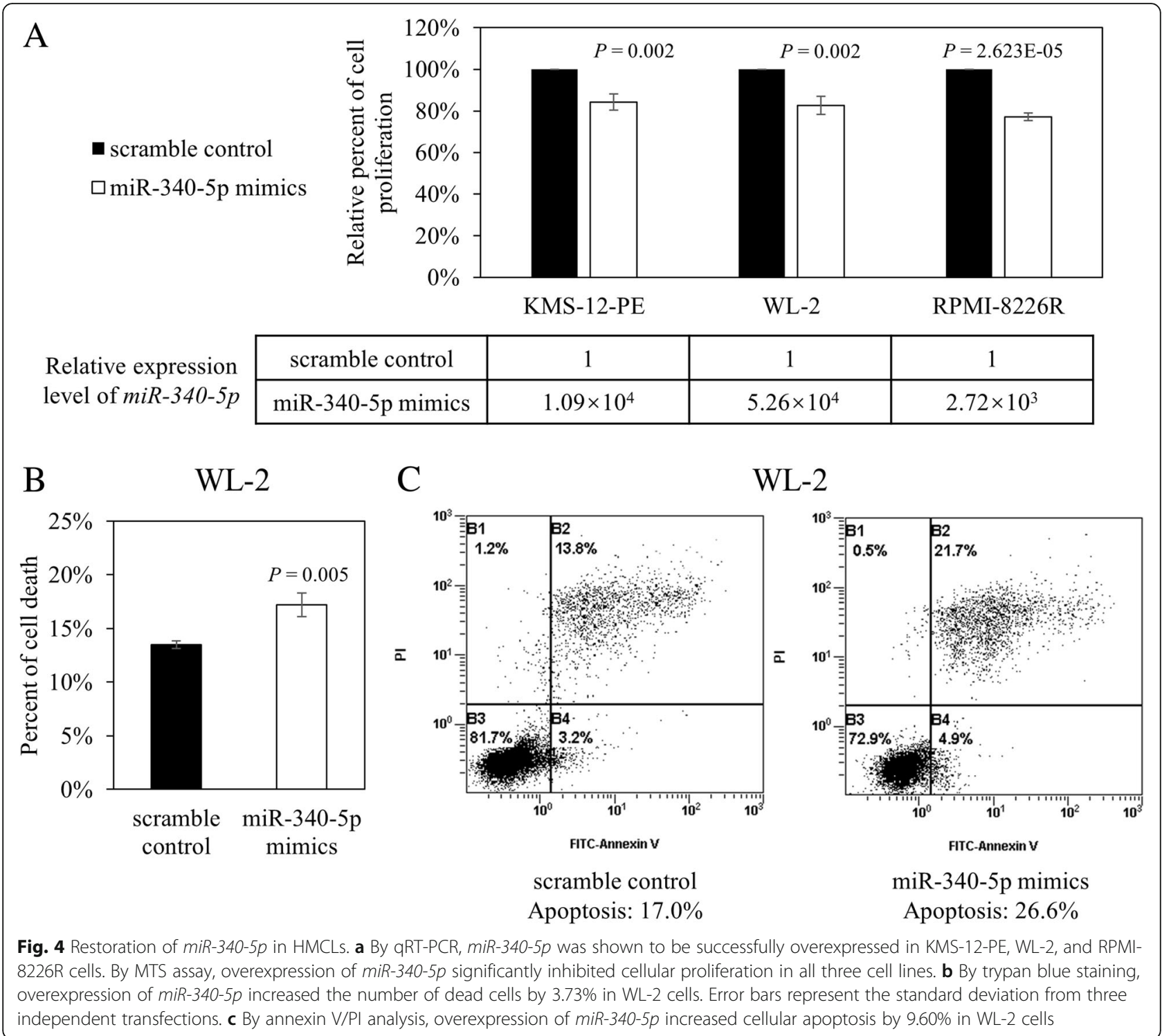

mutant SRBS 1 with miR-340-5p mimics had a similar luciferase activity as compared with scramble control (Additional file 2: Figure S2C). In contrast, upon co-transfection with the wild-type SRBS 2, which was predicted to form 8mer binding with miR-340-5p, overexpression with miR-340-5p mimics (Fig. 6c) led to a reduction of luciferase activity by $34.9 \%$, as compared with scramble control (Fig. 6d; $P=9.981 \mathrm{E}-05)$. Moreover, upon co-transfection of the mutant SRBS 2 with miR-340-5p, the luciferase activity was restored to a comparable level as compared with scramble control (Fig. $6 \mathrm{~d} ; P=0.175$ ). Thus, these data suggested that XIAP is a direct target of miR-340-5p through binding at SRBS 2 in the $3^{\prime}$-UTR.

\section{Discussion}

There are a number of interesting observations in this study.
Firstly, methylation of $m i R-340-5 p$ in myeloma cell lines and primary myeloma cells was tumor-specific as evidenced by the absence of methylation in normal controls, similar to the tumor-specific methylation of other tumor suppressive miRNAs, such as miR-124 [34, 35], $m i R-203$ [24], and miR-34 family miRNAs $[23,36]$ in myeloma. This contrasted with the tissue-specific methylation of miRNAs [37, 38], in which miRNA methylation was detected in both tumor cells and the corresponding normal counterparts, and hence likely unimportant in carcinogenesis.

Secondly, in primary samples, methylation of RNF130/ miR-340 appeared as early as MGUS, at a frequency comparable to that of myeloma at diagnosis and relapsed myeloma. Therefore, it is likely that methylation of RNF130/miR-340 is an early event in the pathogenesis of myeloma, similar to methylation of miR-203 [24] and 


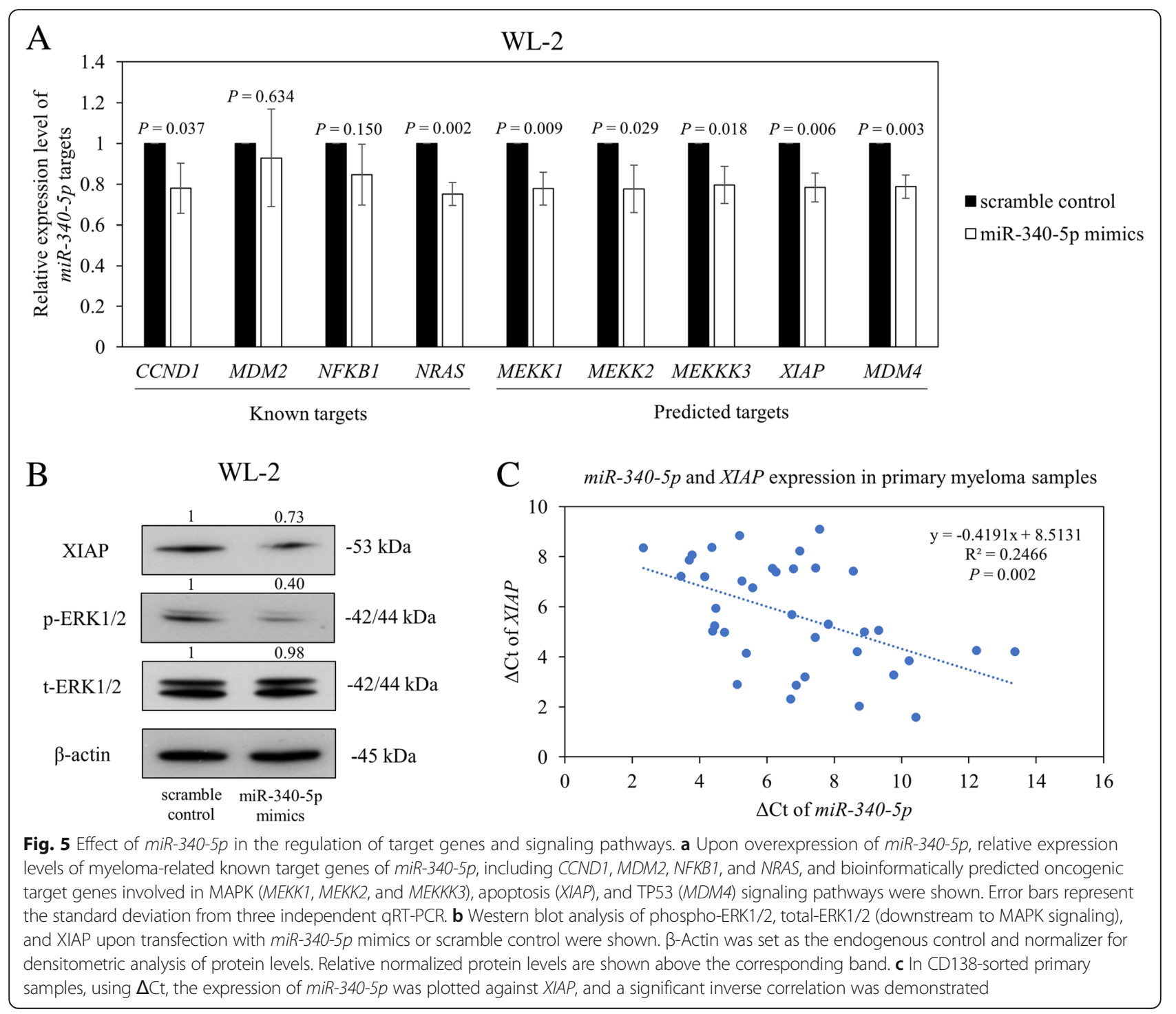

miR-342 [39]. By contrast, miR-129-2 methylation was implicated in the progression from MGUS to symptomatic myeloma [25], and $m i R-34 b / c$ methylation at relapse or progression of myeloma [23]. Moreover, methylation of RNF130/miR-340 correlated with shorter $\mathrm{OS}$ in newly diagnosed myeloma, similar to CDKN2A [40, 41] and DAPK1 [42] methylation. As this cohort of myeloma patients was uniformly treated [43] with bortezomib-based induction regimen, followed by ASCT, and then thalidomide maintenance, methylation of RNF130/miR-340 was a potential novel prognostic marker for myeloma and hence warrants a prospective study in larger cohorts of myeloma samples. Similarly, dysregulated expression of a number of miRNAs, such as $m i R-135 a / b, m i R-200 a / b$, and $m i R-596$, has been shown to carry prognostic impact in myeloma [44]; hence, the prognostic significance of miR-340 expression warrants further investigation.
Thirdly, we showed that the expression of $m i R-340-5 p$ was regulated by promoter hypermethylation of the host gene. First, we showed that miR-340-5p expression correlated with that of $R N F 130$, consistent with the data showing that intronic miRNAs are transcribed in parallel with their host genes, hence are co-regulated [45]. Similarly, when miRNA expression were correlated with gene expression in myeloma cell lines [46], co-expression of 32 pairs of intronic miRNAs and their host genes were found, including miR-340/RNF130. Moreover, we showed low expression of both miR-340-5p and RNF130 in methylated myeloma lines and high expression in unmethylated lines. Furthermore, upon 5-AzadC demethylation, RNF130 promoter demethylation was associated with re-expression of miR-340-5p. Therefore, our data provided additional evidence that intronic miRNAs are silenced by promoter DNA methylation of their host genes $[39,47]$. 


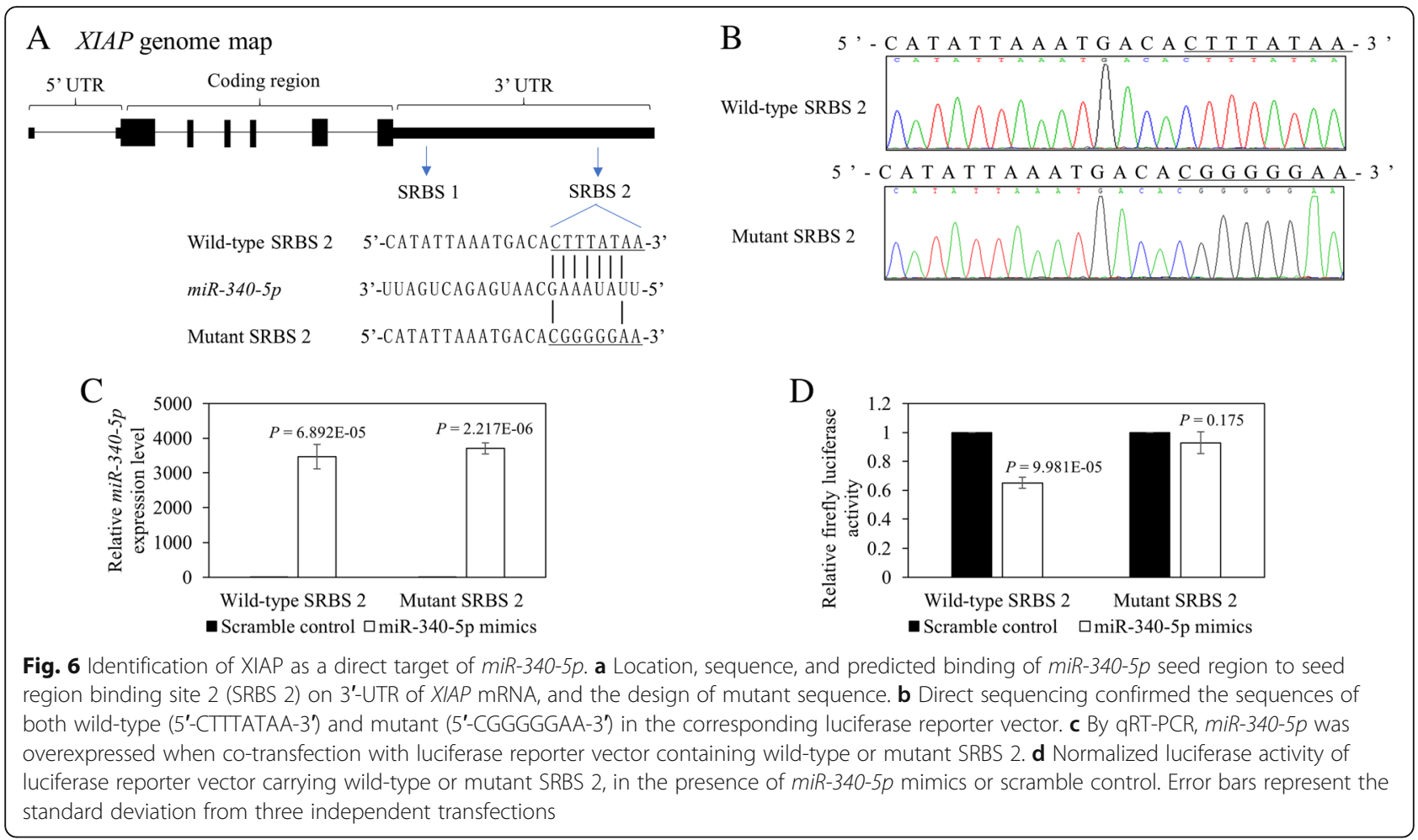

Fourthly, our data demonstrated that miR-340-5p is a tumor suppressor in myeloma. This is supported by the downregulation of mRNA of both known targets (NRAS and $C C N D 1$ ) and bioinformatically predicted targets (MEKK1, MEKK2, MEKKKK3, and XIAP) upon miR-340-5p overexpression. Moreover, by Western blot, the protein level of p-ERK1/2, a key effector of MAPK signaling downstream to NRAS, MEKK1, and MEKKK3, was found repressed upon overexpression of miR-340-5p. Therefore, methylation-mediated silencing of $m i R-340-5 p$ may account for the constitutive activation of MAPK signaling in myeloma pathogenesis [48, 49]. Moreover, overexpression of $m i R-340-5 p$ led to downregulation of CCND1, which is responsible for the transition from $G 1$ to $S$ phase of the cell cycle. Interestingly, upregulation of D-type cyclins is a unified theme in the pathogenesis of myeloma [50]. As CCND1 that encodes for cyclin D1 has been proven to be a direct target of $m i R-340-5 p$ by luciferase assay [32], our data of methylation-mediated silencing of $m i R-340-5 p$ may account for the overexpression of CCND1 in myeloma [50]. On the other hand, we showed that XIAP, an inhibitor of apoptosis and an oncogene overexpressed in multiple cancers, is inversely correlated with and a direct target of miR-340-5p. These are evidenced by, firstly, the lower expression of XIAP correlated with higher expression of miR-340-5p in CD138-sorted primary samples and, secondly, by the suppression of luciferase activity upon co-transfection with miR-340-5p and the WT
XIAP 3' UTR, which was restored by co-transfection with miR-340-5p and the mutant XIAP 3' UTR construct. Interestingly, the suppression of XIAP by miR-340-5p was mediated by the distal (8mer) but not the proximal (7mer-A1) SRBS, hence consistent with the higher predictive value of SRBS by 8 mer than 7 mer-A1 [7]. Indeed, high XIAP expression has been demonstrated in primary myeloma plasma cells and cell lines and yielded larger tumors than myeloma cells with XIAP knock-down in a mouse xenograft model [51]. Therefore, the tumor suppressor activity of $m i R-340-5 p$ was mediated by targeting, and hence downregulation, of XIAP in myeloma. Collectively, these results indicated that miR-340-5p is a tumor suppressor miRNA in myeloma by inhibition of MAPK signaling, cell proliferation, and induction of apoptosis. Conversely, methylation-mediated silencing of miR-340-5p enhanced myeloma plasma cell proliferation via upregulation of CCND1 and MAPK signaling (NRAS/ MEKK1/MEKKK3/p-ERK) in addition to enhancing myeloma cell survival by targeting XIAP. Similarly, miR-340 has been shown to carry tumor suppressor function by inhibiting myeloma cell-induced angiogenesis upon co-culture of myeloma cells with exosomes enriched in miR-340 [52].

\section{Conclusions}

In conclusion, in myeloma, methylation-mediated silencing of miR-340-5p is tumor-specific, reversible, associated with inferior OS, and likely an early event in 
myelomagenesis. Moreover, miR-340-5p potentially exerts its tumor suppressive function via regulation of MAPK signaling and apoptotic pathways.

\section{Methods}

\section{Patient information}

Bone marrow samples were obtained from patients with MGUS $(n=18)$, newly diagnosed myeloma $(n=63)$, and myeloma relapse from complete remission $(n=30)$. Diagnosis of myeloma was based on standard criteria of the International Myeloma Working Group (IMWG) [53]. Complete staging work-up consisted of bone marrow examination, skeletal survey, serum and urine protein electrophoresis, and serum immunoglobulin levels. Of the 63 patients with newly diagnosed myeloma, there were 28 females and 35 males, with a median age of 58 (33-83) years. Apart from 1 patient lacking International Staging System (ISS) data [54], there were 20 stage I, 16 stage II, and 26 stage III cases. There were 8 IgA, 32 IgG, 5 IgD, 14 light chain, and 4 non-secretary myelomas. According to the criteria of the European Group for Blood and Marrow Transplantation Myeloma Registry [55], "relapse" was defined as the reappearance of the same paraprotein detected by serum/urine protein electrophoresis, appearance of new bone lesion or extramedullary plasmacytoma, or unexplained hypercalcemia after prior complete remission. The study has been approved by the Institutional Review Board of Queen Mary Hospital (UW 05-269 T/932), and written informed consent was obtained from patients for the publication of this article and any accompanying data or images.

\section{Treatment}

Transplant-eligible patients with newly diagnosed myeloma were uniformly treated with four cycles of bortezomib-based induction [VTD (bortezomib $1.3 \mathrm{mg} /$ $\mathrm{m}^{2} /$ dose on days $1,8,15$, and 22 ; thalidomide $200 \mathrm{mg} /$ day; and dexamethasone $40 \mathrm{mg} /$ day on days $1,8,15$, and 22)], followed by autologous stem cell transplant (ASCT) conditioned with melphalan $200 \mathrm{mg} / \mathrm{m}^{2}$, and then thalidomide maintenance at a dose of $50 \mathrm{mg} /$ day for 12 months [43]. Treatment response was defined in accordance to the IMWG criteria [56].

\section{Cell culture}

Human myeloma cell lines (HMCLs) KMS-12-PE, MOLP-8, OPM-2, and U-266 were obtained from Deutsche Sammlung von Mikroorganismen und Zellkulturen (DSMZ, Braunschweig, Germany). NCI-H929 was purchased from American Type Culture Collection (ATCC, Manassas, VA, USA). KMS-11/BTZ and OPM-2/BTZ were acquired from Kyowa Hakko Kirin Co. Ltd. (Tokyo, Japan). LP-1 and RPMI-8226 were kindly provided by Prof. Robert Orlowski (Department of Lymphoma/Myeloma, Division of Cancer Medicine, The University of Texas MD Anderson Cancer Center, Houston, TX, USA). JJN-3, OCI-MY5, and RPMI-8226R were kindly provided by Prof. Wee Joo Chng (Department of Medicine, Yong Loo Lin School of Medicine, National University of Singapore). WL-2 was kindly provided by Prof. Andrew Zannettino (Myeloma Research Programme, The University of Adelaide, Australia). MMLAL [57] and MMKKF (unpublished) were established from the myelomatous pleural effusion of myeloma patients. Cell lines were cultured in RPMI-1640 medium (IMDM for LP-1, DMEM + IMDM for MMLAL), supplemented with $10 \%$ or $20 \%$ fetal bovine serum, $50 \mathrm{U} / \mathrm{mL}$ of penicillin, and $50 \mu \mathrm{g} / \mathrm{mL}$ streptomycin, in a humidified atmosphere of $5 \%$ $\mathrm{CO}_{2}$ at $37^{\circ} \mathrm{C}$. All culture reagents were purchased from Invitrogen (Carlsbad, CA, USA). Cell lines obtained from DSMZ and ATCC have been authenticated using short tandem repeat DNA profiling analysis by them. Cells were used for biology assay within 10 passages from thawing.

\section{Methylation-specific polymerase chain reaction (MSP)}

Genomic DNA was extracted using QIAamp DNA Blood Mini Kit (Qiagen, Hilden, Germany), bisulfite-converted using EpiTect Bisulfite Kit (Qiagen), and hence templates for methylated MSP (M-MSP) and unmethylated MSP (U-MSP). Primer sequences and conditions are in Table 1. Detailed procedures of MSP have been previously described $[39,47]$.

\section{Quantitative bisulfite pyrosequencing}

With bisulfite-treated DNA of HMCLs as a template, specific PCR product overlapping the MSP amplicon was amplified by a pair of methylation-unbiased primers using PyroMark PCR Kit (Qiagen). Primer sequences are as follows: forward primer: 5'-GGG TTT TAG GAG GGT TGT AGA A-3'; reverse primer: 5' -biotin-AAA CAT CCC CCA TCC ATA ATA T-3'; condition: $2 \mathrm{mM}$ $\mathrm{MgCl}_{2} / 56^{\circ} \mathrm{C} / 45$ cycles. PCR product was purified, and consecutive $\mathrm{CpG}$ dinucleotides were pyrosequenced with sequencing primer: 5'-GTG TTG GTT GTT TTT TTG TTA-3' or 5'-TGT TTT TTT GTT AGG AGT GAT AGT-3'.

\section{5-Aza-2'-deoxycytidine (5-AzadC) treatment}

WL-2 and RPMI-8226R cells, which were completely methylated for RNF130/miR-340, were treated with $0.5 \mu \mathrm{mol} / 1$ or $1 \mu \mathrm{mol} / 1$ 5-AzadC (Sigma-Aldrich, St. Louis, MO, USA) in fresh medium replaced every 24 hours for 6 days. Cells were harvested for DNA and RNA extraction on both days 3 and 6 . The relative expression level of $m i R-340-5 p$ in the 5-AzadC-treated group against the untreated group was calculated by the $2^{-\Delta \Delta \mathrm{CT}}$ method. 
Table 1 Primer sequences and PCR reaction conditions

\begin{tabular}{|c|c|c|c|c|c|}
\hline $\begin{array}{l}\text { Primer } \\
\text { set }\end{array}$ & Forward primer $\left(5^{\prime}-3^{\prime}\right)$ & Reverse primer $\left(5^{\prime}-3^{\prime}\right)$ & $\begin{array}{l}\text { Product size } \\
\text { (bp) }\end{array}$ & $\begin{array}{l}\mathrm{MgCl}_{2} / \mathrm{Tm} / \\
\text { cycles }\end{array}$ & Reference \\
\hline \multicolumn{6}{|c|}{ (I) Methylation-specific PCR (MSP) of RNF130/miR-340 } \\
\hline M-MSP & TाT CGT AAA TIT TTC GGG TाT TAC & CCG CTA ATC TAA CGA CAA CG & 184 & $\begin{array}{l}2.0 \mathrm{mM} / 58^{\circ} \mathrm{Cl} \\
38\end{array}$ & - \\
\hline U-MSP & TाT TGT AAA TाT TाT GGG TाT TAT & CCC CAC TAA TCT AAC AAC AAC A & 186 & $\begin{array}{l}2.0 \mathrm{mM} / 56^{\circ} \mathrm{Cl} \\
38\end{array}$ & - \\
\hline \multicolumn{6}{|c|}{ (II) Quantitative reverse transcription PCR (qRT-PCR) } \\
\hline MDM2 & GTC GGA AAG ATG GAG CAA G & TGT GAG GTG GTT ACA GCA & 311 & $60^{\circ} \mathrm{C} / 40$ & - \\
\hline NFKB1 & GGC AGC ACT ACT TCT TGA CC & CAG CAA ACA TGG CAG GCT AT & 88 & $60^{\circ} \mathrm{C} / 40$ & [58] \\
\hline NRAS & CGC ACT GAC AAT CCA GCT AA & TCG CCT GTC CTC ATG TAT TG & 177 & $60^{\circ} \mathrm{C} / 40$ & [30] \\
\hline GAPDH & ACC ACA GTC CAT GCC ATC ACT & TCC ACC ACC CTG TTG CTG TA & 452 & $60^{\circ} \mathrm{C} / 40$ & - \\
\hline \multicolumn{6}{|c|}{ (III) Cloning of luciferase reporter constructs with wild-type SRBSs of miR-340-5p } \\
\hline SRBS 1 & AAG GGC TAG CTG TGG TIT CTC TTC GGG GA & $\begin{array}{l}\text { AGG GTC GAC GTT TTG CAG GCG TाT GAA } \\
\text { CA }\end{array}$ & 214 & $\begin{array}{l}1.5 \mathrm{mM} / 60^{\circ} \mathrm{Cl} \\
40\end{array}$ & - \\
\hline SRBS 2 & $\begin{array}{l}\text { AAG GGC TAG CTG GGA CAT AGT TTG AAG } \\
\text { GTG A }\end{array}$ & $\begin{array}{l}\text { AGG GTC GAC TGG ATG CAA AAC CCA } \\
\text { CAG AT }\end{array}$ & 213 & $\begin{array}{l}2.0 \mathrm{mM} / 56^{\circ} \mathrm{C} / \\
35\end{array}$ & - \\
\hline
\end{tabular}

M-MSP methylated MSP, U-MSP unmethylated MSP, Tm annealing temperature, SRBS seed region binding site

\section{Quantitative reverse transcription polymerase chain reaction (qRT-PCR)}

Total RNA was isolated using the mirVana ${ }^{\mathrm{Tm}}$ miRNA Isolation Kit (Ambion). For $m i R-340-5 p$, reverse transcription was performed using the TaqMan MicroRNA RT Kit (ABI, Waltham, MA, USA), followed by qRT-PCR using TaqMan assay (ABI), with RNU48 as the endogenous control. The expression of $m i R-340-5 p$ were analyzed by the $\triangle \mathrm{CT}$ method. Correlation between methylation and expression of $m i R-340-5 p$ was calculated by Student's $t$ test. For other genes, reverse transcription was performed using the QuantiTect Reverse Transcription Kit (QIAGEN). RNF130, MEKK1, MEKK2, $M E K K K 3, X I A P, M D M 4$, and CCND1 were quantified using TaqMan assays (ABI). MDM2, NFKB1, and NRAS were quantified using SYBR Green Master Mix (ABI). $G A P D H$ was used as the endogenous control. Primers are listed in Table 1. The expression of these genes were calculated by the $\triangle \mathrm{CT}$ method. Relative expression of gene in response to overexpression of $m i R-340-5 p$ as compared with scramble control was analyzed by the $2^{-\Delta \Delta C T}$ method.

\section{miR-340-5p overexpression}

Either $m i R-340-5 p$ mimics or scramble oligonucleotides (negative control) (Ambion, Austin, TX, USA) were transfected into $0.5 \times 10^{6} / \mathrm{ml}$ myeloma cells (KMS-12-PE, WL-2, and RPMI-8226R) at a final concentration of 75 nM using Lipofectamine 2000 Transfection Reagent (Invitrogen), according to the manufacturers' instructions.

\section{Trypan blue exclusion assay}

At day 5 after transfection of miR-340-5p mimics or scramble control, cell death was analyzed by trypan blue (Sigma-Aldrich, St. Louis, MO, USA). Cells in five random microscopic fields were counted for each sample under a microscope. Dead cell (stained in blue) percentage is equal to the average number of dead cells per microscopic field over the average number of total cells per microscopic field. Data represents the mean dead cell percentage derived from three independent transfections with triplicate in each.

\section{MTS assay}

The number of viable cells in proliferation was measured by CellTiter $96^{\circ} \mathrm{AQ}_{\text {ueous }}$ One Solution Cell Proliferation Assay Kit (Promega, Madison, WI, USA) following the manufacturers' instructions. The reagent contains a yellowish tetrazolium compound [3-(4,5-dimethylthiazol-2-yl)-5-(3carboxymethoxyphenyl)-2-(4-sulfophenyl)-2H-tetrazolium, inner salt; MTS], which can be bioreduced by live cells into a purple-colored formazan product that is soluble in tissue culture medium and measurable by the colorimetric method. Relative proliferation percentage of miR-340-5p overexpressed cells compared with scramble control was calculated. Data represents the mean relative proliferation percentage derived from three independent transfections with four replicates in each.

\section{Annexin V/propidium iodide ( $\mathrm{PI})$ staining assay}

Cell apoptosis was tested by flow cytometry using FITC Annexin V Apoptosis Detection Kit I (BD Biosciences, 
San Jose, CA, USA). Cells in early apoptosis (suggested by FITC Annexin V positive, PI negative) and late apoptosis (suggested by FITC Annexin V positive, PI positive) are combined as apoptosis cells. Flow cytometry analysis was performed by Cytomics FC 500 Flow Cytometer (Beckman Coulter, Indianapolis, IN, USA).

\section{Western blot}

WL-2 cells transfected with miR-340-5p mimics or scramble oligonucleotides control were harvested and lysed in RIPA buffer (Cell Signaling, Danvers, MA, USA). For each sample, cell lysate containing $10 \mu \mathrm{g}$ protein was separated on Mini-PROTEAN TGX ${ }^{\mathrm{Tm}} 10 \%$ SDS-PAGE gel (Bio-Rad, Hercules, CA, USA) and blotted onto a $0.45 \mu \mathrm{m}$ PVDF membrane (GE Healthcare, Chicago, IL, USA). The membrane was blocked and cut according to protein molecular weight, then incubated in primary antibodies including anti phospho-ERK1/2 (p-ERK1/2; 1:1000; Cell Signaling), anti-total ERK1/2 (t-ERK1/2; 1:1000; Cell Signaling), anti XIAP (1:1000; Cell Signaling), and anti $\beta$-actin (1:2000; Cell Signaling) at $4{ }^{\circ} \mathrm{C}$ overnight. Thereafter, the membranes were washed and incubated with anti-rabbit horseradish peroxidase conjugate secondary antibody at room temperature for $1 \mathrm{~h}$, followed by imaging on X-ray film. Protein bands were quantified using densitometry as measured by Quantity One 4.6.2 software (Bio-Rad).

\section{Plasmid constructs}

The 3'-UTR of XIAP contains two putative SRBSs of miR-340-5p [SRBS1: position 863-869 of 3'-UTR (proximal); SRBS2: position 4927-4934 of 3'-UTR (distal)]. For each SRBS, a wild-type DNA segment of $\sim 200 \mathrm{bp}$ was amplified and cloned into the NheI and SalI sites of a dual firefly/Renilla luciferase reporter vector, pmirGLO (Promega). Mutant DNA segment of each SRBS was synthesized as gBlocks Gene Fragments purchased from Integrated DNA Technologies (Coralville, IA, USA), followed by PCR amplification and cloned into pmirGLO (Promega). The PCR primers are listed in Table 1. Sequencing was employed to confirm both wild-type and mutant constructs.

\section{Luciferase assay}

In 24-well plate, $0.5 \mu \mathrm{g}$ luciferase reporter construct with either wild-type or mutant XIAP 3 '-UTR was co-transfected with $50 \mathrm{nM}$ of either miR-340-5p mimics or scramble oligonucleotide control into HeLa cells (a kind gift from Dr. Zou, Department of Medicine, The University of Hong Kong) using Lipofectamine 2000 (Invitrogen). After $48 \mathrm{~h}$, the luminescent signal was generated and analyzed by Dual-Luciferase Reporter Assay System (Promega). Firefly luciferase activity was normalized by Renilla luciferase activity. Relative luciferase activity of miR-340-5p overexpressed cells compared with scramble control was calculated. Data represents the mean relative luciferase activity derived from three independent transfections with triplicate in each.

\section{Statistical analysis}

The association of RNF130/miR-340 methylation with categorical variables including gender, ISS, and immunoglobulin type was studied by chi-square test, and continuous variable, such as age, by Student's $t$ test. Overall survival (OS) was measured from the date of diagnosis to the date of last follow-up or death. OS of patients with and without RNF130/miR-340 methylation was compared. Survival was plotted by the Kaplan-Meier method and compared by the log-rank test. Cox regression multivariate analysis was performed to analyze the impact of risk factors including RNF130/miR-340 methylation, age, gender, ISS stage, isotype, and high-risk karyotypes [del(17p), $\mathrm{t}(4 ; 14)$, and $\mathrm{t}(14 ; 16)]$ on OS using Statistical Package for the Social Sciences (SPSS) version 19.0. The differences between WL-2 cells transfected with miR-340-5p mimics and scramble oligonucleotide control in trypan blue exclusion assay and MTS assay were studied by Student's $t$ test. All $P$ values were two-sided, and $P<0.05$ was defined as a significant difference.

\section{Additional files}

Additional file 1: Figure S1. Quantitative bisulfite pyrosequencing analysis of RNF130/miR-340 in myeloma cell lines. By detecting the CpG dinucleotides overlapping MSP primer location, the pyrograms of normal, $50 \%$ and positive control showed an expected percentage of methylation. Meanwhile, the pyrograms of cell lines showed consistent result with MSP. (TIF $765 \mathrm{~kb}$ )

Additional file 2: Figure S2. Luciferase assay for SRBS 1. (A) Location and sequence of predicted miR-340-5p seed region binding site 1 (SRBS 1) on XIAP 3'UTR, and the designed mutant sequence. (B) Direct sequencing result showed miR-340-5p SRBS 1 was successfully mutated from 5'-TTTATAA-3' to 5'-GGGGGAA-3'. (C) pmirGLO luciferase constructs containing wild-type or mutant SRBS 1 were co-transfected with miR-340-5p mimics or scramble control into HeLa cells. Luciferase activity was measured at $48 \mathrm{~h}$ after transfection. (TIF 610 kb)

Additional file 3: Figure S3. Schematic diagram adapted from the UCSC Genome Browser showed the genomic organization of miR-340 and its host gene RNF130 on chromosome 5 q35. The promoter region, as indicated by the enrichment of $\mathrm{H} 3 \mathrm{~K} 4 \mathrm{me} 3$ and $\mathrm{H} 3 \mathrm{~K} 27 \mathrm{ac}$, was shown embedded in a CpG island (solid green box). (TIF $325 \mathrm{~kb}$ )

\footnotetext{
Abbreviations

5-AzadC: 5-Aza-2'-deoxycytidine; HMCLs: Human myeloma cell lines; MGUS: Monoclonal gammopathy of undetermined significance; miRNA: MicroRNA; MM: Completely methylated; M-MSP: Methylated MSP; MSP: Methylation-specific PCR; MU: Partially methylated; OS: Overall survival; PCR: Polymerase chain reaction; GRT-PCR: Quantitative real-time PCR; UMSP: Unmethylated MSP; UU: Completely unmethylated
} 


\section{Funding}

This work was supported by the Hong Kong Blood Cancer Foundation and National Natural Science Foundation of China (81470369) awarded to CSC. The funders had no role in the design of the study and collection, analysis, and interpretation of data and in writing the manuscript.

\section{Availability of data and materials}

All data generated or analyzed during this study are included in this published article and its supplementary information files.

\section{Authors' contributions}

ZL carried out the experiments. ZL, KYW, and CSC drafted the manuscript. KYW and CSC conceived and designed the study. GAC advised on the experimental design, and WJC provided the cell lines and additional primary myeloma samples. All authors participated in the analysis and interpretation of data. All authors read and approved the final manuscript.

\section{Ethics approval and consent to participate}

The study has been approved by the Institutional Review Board of Queen Mary Hospital (UW 05-269 T/932), and written informed consent has been obtained from patients for the participation of this study.

\section{Consent for publication}

We have obtained consents from patients for the publication of this report and any accompanying data or images.

\section{Competing interests}

The authors declare that they have no competing interests.

\section{Publisher's Note}

Springer Nature remains neutral with regard to jurisdictional claims in published maps and institutional affiliations.

\section{Author details}

${ }^{1}$ Department of Medicine, Queen Mary Hospital, The University of Hong Kong, Pokfulam Road, Pokfulam, Hong Kong. ${ }^{2}$ Department of Experimental Therapeutics, The University of Texas MD Anderson Cancer Center, Houston, TX, USA. ${ }^{3}$ Cancer Science Institute of Singapore, National University of Singapore, Singapore, Singapore. ${ }^{4}$ Department of Haematology-Oncology, National University Cancer Institute, Singapore, Singapore. ${ }^{5}$ Department of Medicine, Yong Loo Lin School of Medicine, National University of Singapore, Singapore, Singapore. 'Department of Pediatrics and Adolescent Medicine, Queen Mary Hospital, The University of Hong Kong, Pokfulam, Hong Kong.

Received: 29 November 2018 Accepted: 25 April 2019

Published online: 07 May 2019

\section{References}

1. Rajkumar SV. Multiple myeloma: 2016 update on diagnosis, risk-stratification, and management. Am J Hematol. 2016;91(7):719-34.

2. Kyle RA, Rajkumar SV. Monoclonal gammopathy of undetermined significance and multiple myeloma. JAMA Oncol. 2015;1(2):174-5.

3. Morgan GJ, Walker BA, Davies FE. The genetic architecture of multiple myeloma. Nat Rev Cancer. 2012;12(5):335-48.

4. Walker BA, Boyle EM, Wardell CP, Murison A, Begum DB, Dahir NM, Proszek PZ, Johnson DC, Kaiser MF, Melchor L, et al. Mutational spectrum, copy number changes, and outcome: results of a sequencing study of patients with newly diagnosed myeloma. J Clin Oncol. 2015:33(33):3911-20.

5. Lohr JG, Stojanov P, Carter SL, Cruz-Gordillo P, Lawrence MS, Auclair D, Sougnez C, Knoechel B, Gould J, Saksena G, et al. Widespread genetic heterogeneity in multiple myeloma: implications for targeted therapy. Cancer Cell. 2014;25(1):91-101.

6. Chapman MA, Lawrence MS, Keats JJ, Cibulskis K, Sougnez C, Schinzel AC, Harview CL, Brunet JP, Ahmann GJ, Adli M, et al. Initial genome sequencing and analysis of multiple myeloma. Nature. 2011:471(7339):467-72.

7. Bartel DP. MicroRNAs: target recognition and regulatory functions. Cell. 2009:136(2):215-33.

8. Wong KY, Chim CS. DNA methylation of tumor suppressor protein-coding and non-coding genes in multiple myeloma. Epigenomics. 2015;7(6):9851001.

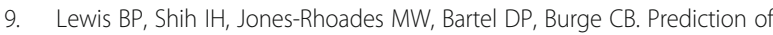
mammalian microRNA targets. Cell. 2003:115(7):787-98.

10. Lawrie CH. MicroRNAs in hematological malignancies. Blood Rev. 2013;27(3): $143-54$.

11. Calin GA, Croce CM. MicroRNA signatures in human cancers. Nat Rev Cancer. 2006;6(11):857-66.

12. Leone E, Morelli E, Di Martino MT, Amodio N, Foresta U, Gulla A, Rossi M, Neri A, Giordano A, Munshi NC, et al. Targeting miR-21 inhibits in vitro and in vivo multiple myeloma cell growth. Clin Cancer Res. 2013; 19(8):2096-106

13. Kramps T, Peter O, Brunner E, Nellen D, Froesch B, Chatterjee S, Murone M, Zullig S, Basler K. Wnt/wingless signaling requires BCL9/legless-mediated recruitment of pygopus to the nuclear beta-catenin-TCF complex. Cell. 2002;109(1):47-60

14. Zhao JJ, Lin J, Zhu D, Wang X, Brooks D, Chen M, Chu ZB, Takada K, Ciccarelli B, Admin S, et al. miR-30-5p functions as a tumor suppressor and novel therapeutic tool by targeting the oncogenic Wnt/beta-catenin/BCL9 pathway. Cancer Res. 2014;74(6):1801-13.

15. Jones PA, Baylin SB. The fundamental role of epigenetic events in cancer. Nat Rev Genet. 2002;3(6):415-28.

16. Fazzari MJ, Greally JM. Epigenomics: beyond CpG islands. Nat Rev Genet. 2004;5(6):446-55.

17. Gardiner-Garden M, Frommer M. CpG islands in vertebrate genomes. J Mol Biol. 1987;196(2):261-82

18. Antequera F. Structure, function and evolution of $\mathrm{CpG}$ island promoters Cell Mol Life Sci. 2003;60(8):1647-58.

19. Robertson KD, Wolffe AP. DNA methylation in health and disease. Nat Rev Genet. 2000:1(1):11-9.

20. Chim CS, Liang R, Kwong YL. Hypermethylation of gene promoters in hematological neoplasia. Hematol Oncol. 2002;20(4):167-76.

21. Lopez-Serra P, Esteller M. DNA methylation-associated silencing of tumorsuppressor microRNAs in cancer. Oncogene. 2012;31(13):1609-22.

22. Chim CS, Kwong YL, Liang R. Gene hypermethylation in multiple myeloma: lessons from a cancer pathway approach. Clin Lymphoma Myeloma. 2008; 8(6):331-9.

23. Wong KY, Yim RL, So CC, Jin DY, Liang R, Chim CS. Epigenetic inactivation of the MIR34B/C in multiple myeloma. Blood. 2011;118(22):5901-4.

24. Wong KY, Liang R, So CC, Jin DY, Costello JF, Chim CS. Epigenetic silencing of MIR203 in multiple myeloma. Br J Haematol. 2011;154(5):569-78.

25. Wong KY, Yim RL, Kwong YL, Leung CY, Hui PK, Cheung F, Liang R, Jin DY, Chim CS. Epigenetic inactivation of the MIR129-2 in hematological malignancies. J Hematol Oncol. 2013;6:16.

26. Qin Y, Zhang S, Deng S, An G, Qin X, Li F, Xu Y, Hao M, Yang Y, Zhou W, et al. Epigenetic silencing of miR-137 induces drug resistance and chromosomal instability by targeting AURKA in multiple myeloma. Leukemia. 2017;31(5):1123-35.

27. Wu ZS, Wu Q, Wang CQ, Wang XN, Huang J, Zhao JJ, Mao SS, Zhang GH, Xu XC, Zhang N. miR-340 inhibition of breast cancer cell migration and invasion through targeting of oncoprotein c-Met. Cancer. 2011;117(13): 2842-52.

28. Li P, Sun Y, Liu Q. MicroRNA-340 induces apoptosis and inhibits metastasis of ovarian cancer cells by inactivation of NF-kB1. Cell Physiol Biochem. 2016; 38(5):1915-27.

29. Yuan J, Ji H, Xiao F, Lin Z, Zhao X, Wang Z, Zhao J, Lu J. MicroRNA-340 inhibits the proliferation and invasion of hepatocellular carcinoma cells by targeting JAK1. Biochem Biophys Res Commun. 2017;483(1):578-84.

30. Fiore D, Donnarumma E, Roscigno G, laboni M, Russo V, Affinito A, Adamo A, De Martino F, Quintavalle C, Romano G, et al. miR-340 predicts glioblastoma survival and modulates key cancer hallmarks through downregulation of NRAS. Oncotarget. 2016;7(15):19531-47.

31. Huang K, Tang Y, He L, Dai Y. MicroRNA-340 inhibits prostate cancer cell proliferation and metastasis by targeting the MDM2-p53 pathway. Onco Rep. 2016;35(2):887-95

32. Li X, Gong X, Chen J, Zhang J, Sun J, Guo M. miR-340 inhibits glioblastoma cell proliferation by suppressing CDK6, cyclin-D1 and cyclin-D2. Biochem Biophys Res Commun. 2015:460(3):670-7.

33. Dweep H, Gretz N. miRWalk2.0: a comprehensive atlas of microRNA-target interactions. Nat Methods. 2015:12(8):697.

34. Wong KY, So CC, Loong F, Chung LP, Lam WW, Liang R, Li GK, Jin DY, Chim CS. Epigenetic inactivation of the miR-124-1 in haematological malignancies. PLoS One. 2011;6(4):e19027. 
35. Lujambio A, Ropero S, Ballestar E, Fraga MF, Cerrato C, Setien F, Casado S, Suarez-Gauthier A, Sanchez-Cespedes M, Git A, et al. Genetic unmasking of an epigenetically silenced microRNA in human cancer cells. Cancer Res. 2007;67(4):1424-9.

36. Chim CS, Wong KY, Qi Y, Loong F, Lam WL, Wong LG, Jin DY, Costello JF, Liang R. Epigenetic inactivation of the miR-34a in hematological malignancies. Carcinogenesis. 2010;31(4):745-50.

37. Wang LQ, Kwong YL, Kho CS, Wong KF, Wong KY, Ferracin M, Calin GA, Chim CS. Epigenetic inactivation of miR-9 family microRNAs in chronic lymphocytic leukemia--implications on constitutive activation of NFkappaB pathway. Mol Cancer. 2013;12:173.

38. Liu RF, Xu X, Huang J, Fei QL, Chen F, Li YD, Han ZG. Down-regulation of miR-517a and miR-517c promotes proliferation of hepatocellular carcinoma cells via targeting Pyk2. Cancer Lett. 2013;329(2):164-73.

39. Li Z, Wong KY, Chan GC, Chng WJ, Chim CS. Epigenetic silencing of EVL/ miR-342 in multiple myeloma. Transl Res. 2018;192:46-53.

40. Galm O, Wilop S, Reichelt J, Jost E, Gehbauer G, Herman JG, Osieka R. DNA methylation changes in multiple myeloma. Leukemia. 2004;18(10):1687-92.

41. Guillerm G, Depil S, Wolowiec D, Quesnel B. Different prognostic values of p15(INK4b) and p16(INK4a) gene methylations in multiple myeloma. Haematologica. 2003;88(4):476-8.

42. Chim CS. Updated survivals and prognostic factor analysis in myeloma treated by a staged approach use of bortezomib/thalidomide/ dexamethasone in transplant eligible patients. J Transl Med. 2010;8:124.

43. Chim CS, Lie AK, Chan EY, Liu HS, Lau CW, Yip SF, Sim J, Wan TS, Ma ES, Liang $\mathrm{R}$, et al. Treatment outcome and prognostic factor analysis in transplant-eligible Chinese myeloma patients receiving bortezomib-based induction regimens including the staged approach, PAD or VTD. J Hematol Oncol. 2012:5:28

44. Seckinger A, Mei $\Delta$ ner T, Moreaux J, Benes V, Hillengass J, Castoldi M, Zimmermann J, Ho AD, Jauch A, Goldschmidt H. miRNAs in multiple myeloma-a survival relevant complex regulator of gene expression. Oncotarget. 2015;6(36):39165.

45. Rodriguez A, Griffiths-Jones S, Ashurst JL, Bradley A. Identification of mammalian microRNA host genes and transcription units. Genome Res. 2004;14(10a):1902-10.

46. Lionetti M, Agnelli L, Mosca L, Fabris S, Andronache A, Todoerti K, Ronchetti D, Deliliers GL, Neri A. Integrative high-resolution microarray analysis of human myeloma cell lines reveals deregulated miRNA expression associated with allelic imbalances and gene expression profiles. Genes Chromosomes Cancer. 2009;48(6):521-31.

47. Li Z, Wong KY, Chan GC, Chim CS. Epigenetic silencing of LPP/miR-28 in multiple myeloma. J Clin Pathol. 2018;71(3):253-8.

48. Xu J, Pfarr N, Endris V, Mai EK, Md Hanafiah NH, Lehners N, Penzel R, Weichert W, Ho AD, Schirmacher P, et al. Molecular signaling in multiple myeloma: association of RAS/RAF mutations and MEKJERK pathway activation. Oncogenesis. 2017;6(5):e337.

49. Lionetti M, Barbieri M, Todoerti K, Agnelli L, Marzorati S, Fabris S, Ciceri G, Galletti S, Milesi G, Manzoni M, et al. Molecular spectrum of BRAF, NRAS and KRAS gene mutations in plasma cell dyscrasias: implication for MEK-ERK pathway activation. Oncotarget. 2015;6(27):24205-17.

50. Bergsagel PL, Kuehl WM, Zhan F, Sawyer J, Barlogie B, Shaughnessy J Jr. Cyclin D dysregulation: an early and unifying pathogenic event in multiple myeloma. Blood. 2005;106(1):296-303.

51. Desplanques G, Giuliani N, Delsignore R, Rizzoli V, Bataille R, Barille-Nion S. Impact of XIAP protein levels on the survival of myeloma cells. Haematologica. 2009;94(1):87-93.

52. Umezu T, Imanishi S, Azuma K, Kobayashi C, Yoshizawa S, Ohyashiki K, Ohyashiki JH. Replenishing exosomes from older bone marrow stromal cells with miR-340 inhibits myeloma-related angiogenesis. Blood advances. 2017; 1(13):812-23.

53. International Myeloma Working Group. Criteria for the classification of monoclonal gammopathies, multiple myeloma and related disorders: a report of the International Myeloma Working Group. Br J Haematol. 2003; 121(5):749-57.

54. Greipp PR, San Miguel J, Durie BG, Crowley JJ, Barlogie B, Blade J, Boccadoro M, Child JA, Avet-Loiseau H, Kyle RA, et al. International staging system for multiple myeloma. J Clin Oncol. 2005;23(15):3412-20.

55. Blade J, Samson D, Reece D, Apperley J, Bjorkstrand B, Gahrton G, Gertz M, Giralt S, Jagannath S, Vesole D. Criteria for evaluating disease response and progression in patients with multiple myeloma treated by high-dose therapy and haemopoietic stem cell transplantation. Myeloma Subcommittee of the EBMT. European Group for Blood and Marrow Transplant. Br J Haematol. 1998;102(5):1115-23.

56. Rajkumar SV, Harousseau JL, Durie B, Anderson KC, Dimopoulos M, Kyle R, Blade J, Richardson P, Orlowski R, Siegel D, et al. Consensus recommendations for the uniform reporting of clinical trials: report of the International Myeloma Workshop Consensus Panel 1. Blood. 2011;117(18): 4691-5.

57. Wong KY, Wan TS, So CC, Chim CS. Establishment of a bortezomib-resistant Chinese human multiple myeloma cell line: MMLAL. Cancer Cell Int. 2013; 13(1):122.

58. Huang T, Kang W, Zhang B, Wu F, Dong Y, Tong JH, Yang W, Zhou Y, Zhang L, Cheng AS, et al. miR-508-3p concordantly silences NFKB1 and RELA to inactivate canonical NF-kappaB signaling in gastric carcinogenesis. Mol Cancer. 2016:15:9

\section{Ready to submit your research? Choose BMC and benefit from:}

- fast, convenient online submission

- thorough peer review by experienced researchers in your field

- rapid publication on acceptance

- support for research data, including large and complex data types

- gold Open Access which fosters wider collaboration and increased citations

- maximum visibility for your research: over $100 \mathrm{M}$ website views per year

At BMC, research is always in progress.

Learn more biomedcentral.com/submissions 